\title{
COVID-19: What Do We Have Learnt So Far?
}

\author{
Samreen Kulsoom Zaidi*
}

Department of Paediatrics, National Institute of Blood Disease \& Bone Marrow Transplantation, Karachi, Pakistan.

Coronaviruses (CoVs) are the largest group of viruses; order is Nidovirales while family is Coronaviridae. They are further subdivided into four groups, the alpha, beta, gamma and delta coronaviruses [1]. These viruses usually cause mild infections but two zoonotic epidemics of the betacoronaviruses, severe acute respiratory syndrome coronavirus (SARS-CoV) [2] and Middle East respiratory syndrome coronavirus (MERS-CoV) [3] have occurred in this century, mortality rates of $10 \%$ for SARS-CoV [4] while a very high i.e. $37 \%$ for MERS-CoV [5].

The third zoonotic human coronavirus $(\mathrm{CoV})$ that has emerged recently in December 2019, with a bunch of people identified first in Huanan South China Seafood Market in Wuhan, China. Earlier cases were reported as a new pneumonia but later confirmed as a betacoronavirus by real-time RT-PCR and next-generation sequencing. World Health Organization named this new zoonotic betacoronavirus as COVID-19 [6]. Initially it was recognized as a public health emergency of international concern (PHEIC) by WHO on 30th January 20 [7] but due to the rapid spread leading to 13 fold increase in cases worldwide it was declared as a 'Pandemic' on 11th March 2020 [8].

The clinical presentation of COVID is variable from asymptomatic to fatal illness. Recent literature has divided disease into three types depending on the severity of disease. Majority of the people fall into 'uncomplicated (mild) Illness' group while some with cough and shortness of breath are classified as 'Moderate Pneumonia'. Severe pneumonia is the category where along with other symptoms hypoxia $(\mathrm{SpO} 2<90 \%$ on room air) is also present which may evolve into Acute Respiratory Distress Syndrome, Sepsis and Septic Shock [9].

Emergence of SARSCoV2, like other two coronaviruses, is presumed to be from bats and later person to person contact through droplets has resulted in this zoonotic pandemic [10]. There are many concerns regarding airborne transmission and studies are still going on but till date no evidence has proven this mode of transmission [11]. There was also suspicion of vertical transmission as noted in previous Coronaviruses [12] but clinical evidence of nine women in her last trimester who had laboratory-confirmed COVID-19 pneumonia has shown that there is currently no evidence for perinatal infection and antibodies against SARS CoV2 do not cross placenta [13].

*Address correspondence to this author at the Department of Paediatrics, National Institute of Blood Disease \& Bone Marrow Transplantation Karachi, Pakistan. E-mail: samreenkulsoom@gmail.com
The only other way documented for transmission is fomites in the immediate environment of infected person. The life of virus is long, on copper it is viable for almost four hours while on cardboard for a day and on plastic and stainless steel materials is up to three days [14]. However their growth can be adequately halted by surface disinfection procedures with $62-71 \%$ ethanol, $0.5 \%$ hydrogen peroxide or $0.1 \%$ sodium hypochlorite within 1 minute [15] so regular cleaning of fomites is recommended to interrupt the transmission.

As already mentioned the disease has variable presentation and possibilities for severe illness are not apparent yet. Most reported cases shown have occurred in adults. In retrospective analysis in China, 425 patients with pneumonia and confirmed 2019-nCoV infection, male sex was more than half (almost 57\%). While about one-third to one-half of reported patients had other primary medical illnesses that included hypertension, cardiovascular disease and diabetes. In another study, age is found to be an important factor for the severity of disease and mostly patients with severe illness were older (median age 66 years vs 51 years) and were had underlying co-morbid conditions ( $72 \%$ versus $37 \%$ ) [16-19]. The diagnosis can be confirmed only by Real-Time RT-PCR Panel for Detection 2019-Novel Coronavirus on respiratory secretions, although there are some clinical features that might aid in diagnosis are lekopenia (9-25\%), leukocytosis (24-30\%), lymphopenia (63\%), and deranged liver functions (37\%). However, there was no evidence of bacterial infection as most of the patients had normal levels of procalcitonin on admission. Chest CAT scan has shown bilateral involvement of lungs in majority of patients. The commonly reported findings were areas of consolidation and ground glass opacities [16-19].

The management of COVID-19 is not very clear yet. In mild to moderate cases it is close observation and can be done either as an inpatient or outpatient but the decision should be taken by reviewing every case thoroughly. The disease progresses and worsens in second week of illness [20] and treatment guidelines are released by Infectious Diseases Society of America (IDSA). There is no specific treatment and only recommendations are made for hydroxychloroquine/chloroquine, hydroxychloroquine/chloroquine plus azithromycin, the combination of lopinavir/ritonavir and tocilizumab but in context of clinical trials only [21]. The other option given is use of convalescent plasma but again for a clinical trial. Routine use of corticosteroids is discouraged 
but can be used if there are other indications for example like sepsis leading to shock or any other concomitant respiratory illnesses. This recommendation is made on the previous evidence that there is a possibility of viral replication prolongation as it was observed in patients with MERS-CoV [22].

Thus far, globally 2,127,873 laboratory-confirmed have been reported while deaths are 141,454 . The rise in cases showed that there is already exponential growth and it has already overburdened the health care system of Italy, France and United States. This rapid progression and no available treatment and vaccine for prevention are global concerns. So far the world has introduced a bundle of prevention measures that include testing of suspected person, contact tracing, quarantine, social distancing and very importantly hand hygiene. However, these measures will not eradicate the disease but will buy time for development of treatment and preventive strategies which is the ultimate goal. A recent transmission projection showed that social distancing should be prolonged not only till the invention of treatment and vaccine but till 2024 as there is a chance of resurgence after the initial pandemic wave [23]. We assume that the desperate efforts for the prevention and treatment of this pandemic will show results in near future but there are few points that need to be highlighted to prevent such widespread future epidemics. One of them is the consumption of raw meat and live wild animals. In Chinese mukbags they broadcast consumption of animals which should be discouraged [24]. The other point was delay in early detection and early reporting. Scientists in China detected a new pneumonia in eight patients in early December but action was taken and almost 5 million people moved out of Wuhan to go home for Chinese New Year or travel abroad [25]. Special attention should be paid to avoid such disasters in future.

Since the outbreak of COVID-19 many aspects are still hidden and scientists are working hard to depict a clear picture. WHO along with other authorities is putting all efforts to interrupt the transmission and to find an effective treatment option for this pandemic. It is expected that in a short of span of time human will be able to take control of this novel coronavirus disease.

Educational background and encourage making it mandatory for healthcare-workers to hold multiple counseling sessions with their patients upon admission and during the stay.

\section{CONFLICT OF INTEREST}

Declared none.

\section{ACKNOWLEDGEMENTS}

Declared none.

\section{REFERENCES}

[1] Ksiazek TG, Erdman D, Goldsmith CS, et al. A novel coronavirus associated with severe acute respiratory syndrome. New Engl J Med 2003; 348(20): 1953-66. DOI: 10.1056/NEJMoa030781

[2] Zaki AM, Van Boheemen S, Bestebroer TM, Osterhaus AD, Fouchier RA. Isolation of a novel coronavirus from a man with pneumonia in Saudi Arabia. New Engl J Med 2012; 367(19): 1814-20. DOI: 10.1056/NEJMoa1211721

[3] WHO. Summary of probable SARS cases with onset of illness from 1 November 2002 to 31 July 2003. 2003; Available at: https://www.who.int/csr/sars/country/table2004_04_21/en/

[4] WHO. Middle East respiratory syndrome coronavirus (MERS-CoV). 2019; Available at: https://www.who.int/emergencies/mers-cov/en/

[5] Gralinski LE, Menachery VD. Return of the Coronavirus: 2019-nCoV. Viruses 2020; 12(2): 135.

DOI: $10.3390 / \mathrm{v} 12020135$

[6] Berkley Jr. World Health Organization names the new coronavirus: COVID-19. 2020; Available from: https://www.cnbc.com/2020/02/11/world-health-organization-names-the-new-coronavirus-covid-19.html

[7] Statement on the second meeting of the International Health Regulations (2005) Emergency Committee regarding the outbreak of novel coronavirus (2019-nCoV). 2020; Available from: https://www.who.int/news-room/d tail/30-01-2020statement-on-the-second-meeting-of-the-international-health-regulations-(2005)-emergency-committee-regarding -the-outbreak-of-novel-coronavirus-(2019-ncov).

[8] Cucinotta D, Vanelli M. WHO declares COVID-19 a pandemic. Acta Biomed 2020; 91(1): 157-60.

[9] Cascella M, Rajnik M, Cuomo A, Dulebohn SC, Di Napoli R. Features, evaluation and treatment coronavirus (COVID-19). Treasure Island (FL): StatPearls Publishing 2020.

[10] WHO. Modes of transmission of virus causing COVID-19: Implications for IPC precaution recommendations. Scientific Brief 2020; Available at: https:/www.who.in$\mathrm{t} / \mathrm{n}$ e w s - r o o m / c o m m e n t a r i e s/d e t a i $1 /$ modes-of-transmission-of-virus-causing-covid-19-implicatio ns-for-ipc-precaution-recommendations.

[11] Ong SWX, Tan YK, Chia PY, et al. Air, surface environmental, and personal protective equipment contamination by severe acute respiratory syndrome coronavirus 2 (SARS-CoV-2) from a symptomatic patient. JAMA 2020; 323(16): 1610-2. DOI: 10.1001/jama.2020.3227

[12] Favre G, Pomar L, Musso D, Baud D. 2019-nCoV epidemic: What about pregnancies? Lancet 2020; 395(10224): e40. DOI: 10.1016/S0140-6736(20)30311-1 
[13] Chen H, Guo J, Wang C, et al. Clinical characteristics and intrauterine vertical transmission potential of COVID-19 infection in nine pregnant women: A retrospective review of medical records. Lancet 2020; 395(10226): 809-15. DOI: 10.1016/S0140-6736(20)30360-3

[14] van Doremalen N, Bushmaker T, Morris DH, et al. Aerosol and surface stability of SARS-CoV-2 as compared with SARS-CoV-1. New Engl J Med 2020; 382(16): 1564-7. DOI: 10.1056/NEJMc2004973

[15] Kampf G, Todt D, Pfaender S, Steinmann E. Persistence of coronaviruses on inanimate surfaces and its inactivation with biocidal agents. J Hosp Infect 2020; 104: 246-51. DOI: 10.1016/j.jhin.2020.01.022

[16] Li Q, Guan X, Wu P, et al. Early transmission dynamics in Wuhan, China, of novel coronavirus-infected pneumonia. New Engl J Med 2020; 382(13): 1199-1207. DOI: 10.1056/NEJMoa2001316

[17] Huang C, Wang Y, Li X, et al. Clinical features of patients infected with 2019 novel coronavirus in Wuhan, China. Lancet 2020; 395(10223): 497-506.

DOI: $10.1016 / \mathrm{S} 0140-6736(20) 30183-5$

[18] Ozma MA, Maroufi P, Khodadadi E, et al. Clinical manifestation, diagnosis, prevention and control of SARS-CoV-2 (Covid-19) during the outbreak period. Infez Med 2020; 28(2): 153-65.

[19] Wang D, Hu B, Hu C, et al. Clinical characteristics of 138 hospitalized patients with 2019 novel coronavirus-infected pneumonia in Wuhan, China. JAMA 2020; 323(11): 1061-9. DOI: $10.1001 /$ jama.2020.1585

[20] CDC. Interim clinical guidance for management of patients with confirmed coronavirus disease (COVID-19). 2020; Available at: https://www.cdc.gov/coronavirus/2019-ncov/h$\mathrm{cp} /$ clinical-guidance-management-patients.html [Accessed : May 29, 2020].

[21] Bhimraj A, Morgan RL, Shumaker AH, et al. Infectious diseases Society of America guidelines on the treatment and management of patients with COVID-19. Clin Infect Dis 2020; ciaa478. DOI: $10.1093 / \mathrm{cid} / \mathrm{ciaa} 478$

[22] Arabi YM, Mandourah Y, Al-Hameed F, et al. Corticosteroid therapy for critically ill patients with Middle East respiratory syndrome. Am J Respir Crit Care Med 2018; 197(6): 757-67. DOI: $10.1164 / \mathrm{rccm} .201706-1172 \mathrm{OC}$

[23] Kissler SM, Tedijanto C, Goldstein E, Grad YH, Lipsitch M. Projecting the transmission dynamics of SARS-CoV-2 through the postpandemic period. Science 2020; 368(6493): 860-8. DOI: $10.1126 /$ science.abb5793

[24] Li J, Li JJ, Xie X, et al. Game consumption and the 2019 novel coronavirus. Lancet Infect Dis 2020; 20(3): 275-6. DOI: 10.1016/S1473-3099(20)30063-3

[25] Zhou P, Yang X-L, Wang X-G, et al. A pneumonia outbreak associated with a new coronavirus of probable bat origin. Nature 2020; 579: 270-3. DOI: 10.1038/s41586-020-2012-7 